Article

\title{
Application of a Double-Sided Chance-Constrained Integer Linear Program for Optimization of the Incremental Value of Ecosystem Services in Jilin Province, China
}

\author{
Baofeng Cai ${ }^{1}$, Xianen Wang ${ }^{1, *}$ and $\mathrm{Yu} \mathrm{Li}^{2, *}$ \\ 1 College of Environment and Resources, Jilin University, Changchun 130012, China; cbf777@sohu.com \\ 2 The State Key Laboratory of Regional Optimisation of Energy System, North China Electric \\ Power University, Beijing 102206, China \\ * Correspondence: wxen@jlu.edu.cn (X.W.); liyuxx8@hotmail.com (Y.L.); \\ Tel.: +86-431-85168429 (X.W.); +86-10-61773886 (Y.L.)
}

Received: 27 June 2017; Accepted: 16 August 2017; Published: 22 August 2017

\begin{abstract}
The Interconnected River System Network Project (IRSNP) is a significant water supply engineering project, which is capable of effectively utilizing flood resources to generate ecological value, by connecting 198 lakes and ponds in western Jilin, northeast China. In this article, an optimization research approach has been proposed to maximize the incremental value of IRSNP ecosystem services. A double-sided chance-constrained integer linear program (DCCILP) method has been proposed to support the optimization, which can deal with uncertainties presented as integers or random parameters that appear on both sides of the decision variable at the same time. The optimal scheme indicates that after rational optimization, the total incremental value of ecosystem services from the interconnected river system network project increased $22.25 \%$, providing an increase in benefits of $3.26 \times 10^{9} ¥$ compared to the original scheme. Most of the functional area is swamp wetland, which provides the greatest ecological benefits. Adjustment services increased obviously, implying that the optimization scheme prioritizes ecological benefits rather than supply and production services.
\end{abstract}

Keywords: incremental value of ecosystem service; double-sided chance-constrained integer linear program; interconnected river system network project; optimization; utilization of flood resource

\section{Introduction}

Ecosystem services are critical for human existence, development, and wellbeing. In recent decades, significant progress has been made regarding the theory and assessment technologies used for ecosystem service evaluation [1-7]. A benefit analysis of water infrastructure engineering based on ecosystem service benefits can improve the evaluation of wetland restoration projects in particular, and ecosystem restoration in general.

Floodwater is always treated as one kind of natural disaster. In fact, when rationally utilized and optimally configured, it can be a fresh water resource, and additional benefits will be generated to the economy and society through the sustainable use of the water resource. The interconnected river system network project (IRSNP) in western Jilin Province is a typical example of water supply engineering that can efficiently utilize flood resources to restore wetland areas, which represents a major role in ecological value regeneration, and has a significant impact on local ecological economic development and human habitation improvement. The project will create an interconnected river system network, combining water diversion, $s$ torage, irrigation, drainage, and lifting. The project depends on the natural water system and hydraulic engineering, and will incorporate engineering measures such 
as the extension of the channel, pump stations, and sluice gates. The interconnected waterways will allow floodwater to be used for augmenting important lakes in western Jilin, maintaining freshwater, supplying groundwater, and improving the eco-environment. The project will help various services such as food production, raw material production, water supply, carbon sequestration, atmosphere regulation, water regulation and storage, microclimate adjustment, the prevention of degradation by pollution, biodiversity protection, scientific culture, tourism, and landscape aesthetics. The total incremental value of the ecosystem services is approximately $10^{11} ¥$, and will bring significant ecological, social, and economic benefits from flood and irrigation resources [8,9].

During evaluation and optimization of the incremental value of ecosystem services, uncertainties that result from natural processes and human activities make the system more complex. Uncertainties that are presented as random information exist especially in the hydrological cycle, variation in the water environment over time and space, or estimation errors on parameters [10-12]. Chance-constrained programming (CCP) is the most typical stochastic mathematical programming (SMP) method to present and deal with uncertainty expressed as random information, which can be easily integrated with other optimization approaches to deal with multiform uncertainties $[1,13,14]$. However, few researches have been reported that can represent random variables in the double-hand-side of the constraints applied to the optimization problem in ecosystem services.

In this article, a double-sided chance-constrained integer linear program (DCCILP) method has been proposed, integrating double-hand-side chance-constrained programming (DCCP) with the integer linear program, and applied to optimize the incremental value of ecosystem services. In the optimal model, maximization of the incremental value of ecosystem services has been selected as the objective function; regional water supply, the cultivation function of the ponds, $0-1$ issues, and water demand are taken as constraints. Random information, such as water demand per unit and water supply for service regions, set as random numbers, have been presented and transformed.

\section{Study Area}

The study area is in the western Jilin Province, China. The western part of Jilin Province occurs in a semi-arid temperate climate zone, where water shortages and uneven distribution of surface water occurs. In addition to desertification and salinization, alternating droughts and flood occur, therefore, the rational utilization and configuration of water resources is extremely urgent. Western Jilin is also an agricultural heartland and a key ecosystem environment region. In order to improve the ecosystem environment of this region, the Jilin provincial party committee and provincial government proposed an IRSNP in western Jilin Province.

The area of the proposed IRSNP covers Zhenlai, Taobei, Taonan, Da'an, Tongyu, Qianguo, Qian'an, and Nong'an, which are located on the western plain of the right bank of the Nen River, and the left bank of the Songhua River. The project will connect 198 water bodies including lakes, ponds, and reservoirs, and involves national nature reserves such as Xianghai, Momoge, Chagan Lake, and Boluo Lake, covering an area of 4.46 million square kilometers which makes up $23.8 \%$ of Jilin Province. The project has been listed in "The 13th Five Year Plan" by the State Council of China as a key water conservation project, and aims to make optimal use of flood resources and irrigation return flow to restore wetlands, in order to rationally utilize and optimally configure water resources and further improve the eco-environment.

The project can improve water resources in the following ways: (1) restore wetlands and improve the eco-environment of western Jilin; (2) recharge groundwater and restore the ecological water level; (3) transfer economic development modes and increase the income of local peasants; (4) fully implement flood diversion to lakes and ponds.

The map of the IRSNP in western Jilin Province is shown in Figure 1. 


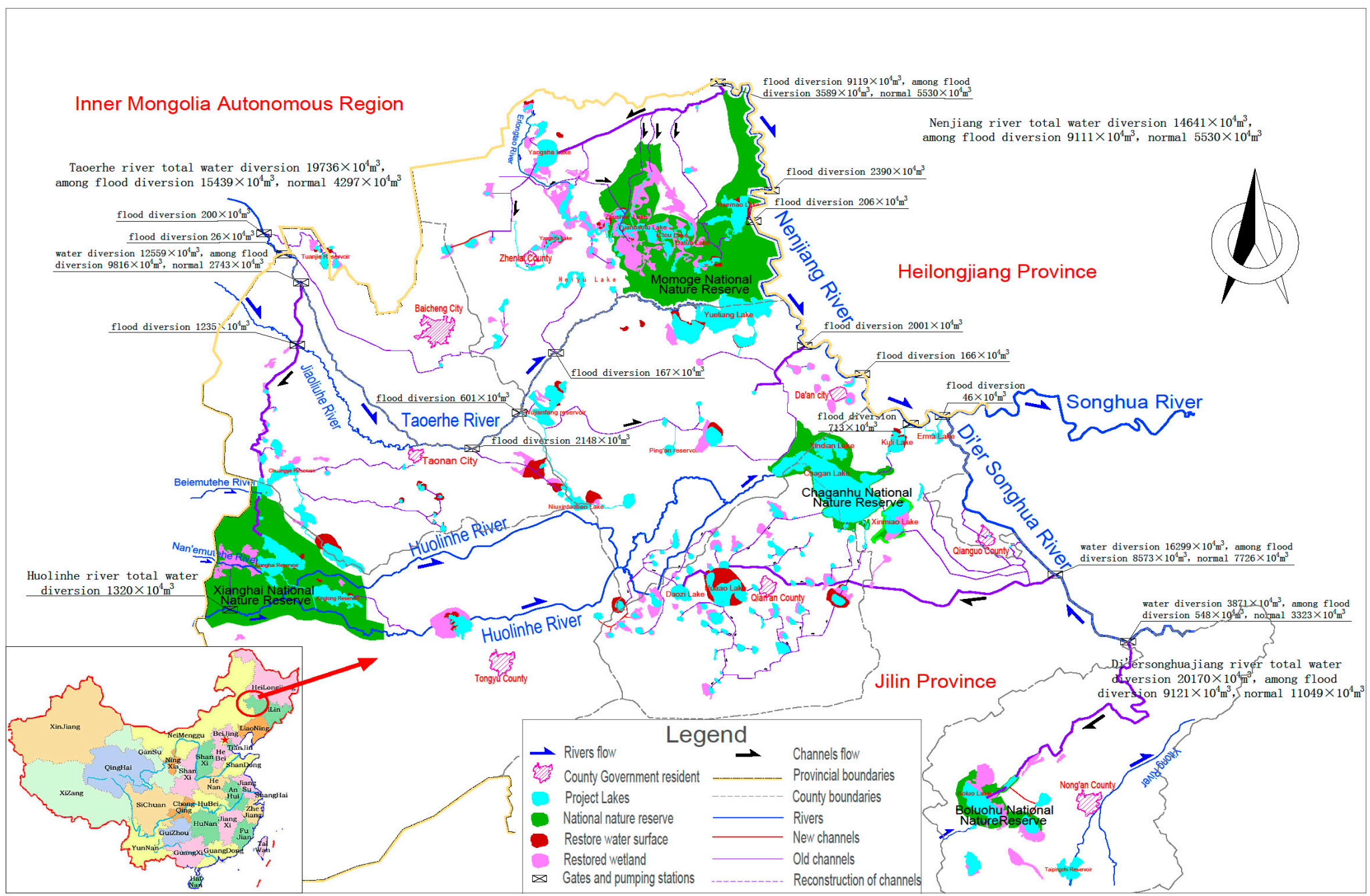

Figure 1. Interconnected River System Network Project (IRSNP). 


\section{Assessment Index System and Calculation of the Incremental Value of Ecosystem Services}

\subsection{Establishment of an Assessment Index System}

An assessment index system was established to enable the evaluation of the incremental value of ecosystem services in western Jilin.

The salient principles of the assessment index system [15-20] are as follows:

(1) Representativeness and pertinence

The index system should be concise and to the point. The indices selected should be representative of the service value of the eco-environment.

(2) Independence

There should be no significant impact between each index-Indices of the same type should be independent of each other.

(3) Feasibility

The index system should consider the environmental conditions that are impacted by the natural world and human society.

(4) Other principles

The index system should take the functional characteristics of western Jilin into consideration, and contain as many factors that can affect ecological service value as possible.

Using the above principles and the wetland system characteristics, an index system was established including 4 first-class indices, 12 second-class indices, and 15 third-class indices (Table 1). The specific descriptions are shown in Section 3.2.

Table 1. Assessment index system for the incremental value of ecosystem services.

\begin{tabular}{lll}
\hline First-Class Indices & Second-Class Indices & Third-Class Indices \\
\hline \multirow{2}{*}{ Supply service } & Food production & $\begin{array}{l}\text { Fish } \\
\text { Crab }\end{array}$ \\
\cline { 2 - 3 } & Raw material production & Reed \\
\cline { 2 - 3 } & Water supply & Water supply \\
\hline \multirow{3}{*}{ Adjustment service } & Carbon sequestration & Carbon sequestration \\
& Atmosphere regulation & Oxygen release \\
& Water regulation and storage & Water storage and regulation \\
& Microclimate adjustment & Microclimatic modification \\
\hline \multirow{3}{*}{ Support service } & Pollution degradation & Plant fixation \\
& Assimilative capacity \\
\cline { 2 - 3 } & Biodiversity protection & Biodiversity \\
\hline \multirow{2}{*}{ Cultural services } & Scientific culture & Scientific culture \\
& Tourism development & Tourism development \\
\cline { 2 - 3 } & Landscape aesthetics & Urban landscape \\
& & Nature landscape \\
\hline
\end{tabular}

\subsection{Calculation of Incremental Values of Ecosystem Services}

The calculation of the incremental values of ecosystem services uses the assessment index system.

\subsubsection{Food Production}

The ecosystem service value of food production includes fish and crab, and can be calculated using the market valuation method [21]: 


$$
V_{s}=\sum_{i=1}^{n} A_{i} \cdot Y_{i} \cdot P_{i}
$$

where $V_{S}$ is the food production value, $A$ is the cultivated area, $Y$ is the output of produce $i$, and $P$ is the price of the produce $i$. The output and the price of fish is $80 \mathrm{~kg} / \mathrm{ha}$ and $20 ¥ / \mathrm{kg}$, respectively, while the output and the price of crab is $80 \mathrm{~kg} / \mathrm{ha}$ and $30 ¥ / \mathrm{kg}$, respectively.

\subsubsection{Raw Material Production}

Western Jilin is the major reed production area for Jilin Province. Reed has economic and ecological benefits. The material production benefit of reed can be determined by the market valuation method:

$$
V_{m}=A \cdot C \cdot P_{m}
$$

where $V_{m}$ is the raw material production value, $A$ is the reed area, $C$ is the output of reed, and $P_{m}$ is the price of reed. The output and the price of reed is $300 \mathrm{~kg} / \mathrm{ha}$ and $0.4 ¥ / \mathrm{kg}$, respectively.

\subsubsection{Water Supply}

Wetlands have a strong influence on water storage, and can provide water resources for domestic use, agriculture, and industry. Water supply benefits from wetlands can be expressed as:

$$
V_{w}=A \cdot P_{w}
$$

where $V_{w}$ is the water supply value, A is the wetland area, $P_{w}$ is the water supply price for wetlands which is $775.39 ¥ /$ ha.

\subsubsection{Carbon Sequestration}

Wetlands can sequestrate carbon through photosynthesis. The biomass of reeds wetland and swamp wetland are $300 \mathrm{~kg} / \mathrm{ha}$ and $50 \mathrm{~kg} / \mathrm{ha}$, respectively, from which the total biomass in the study area can be determined. The carbon sequestration amount for wetlands can be gained from the photosynthesis equation, using $0.44 \mathrm{C} / \mathrm{g}$ for dry matter.

$$
V_{1}=W_{1} \times P
$$

where $V_{1}$ is the carbon sequestration value, $W_{1}$ is the carbon sequestration quantity, $P$ is the price of carbon sequestration per unit, and $P$ is $277.7 ¥ / \mathrm{t}$ [22].

\subsubsection{Atmosphere Regulation}

Wetlands can help regulate the atmosphere by releasing oxygen into the atmosphere. This benefit can be accounted for as follows:

$$
V_{0}=1.2 \cdot \mathrm{W} \cdot P_{0}
$$

where $V_{0}$ is the value of oxygen released, $W$ is the biomass of the wetland, $P_{0}$ is the price of $\mathrm{O}_{2}$, and $P_{0}$ is set at $1000 ¥ / \mathrm{t}$.

\subsubsection{Water Regulation and Storage}

Wetlands can have a significant influence on water storage and recharge, including the regulation of floods by wetlands and storage by ponds. The water regulation and storage benefit can be calculated by the replacement cost method [21]:

$$
V_{r}=\left(W_{s}+W_{r}\right) \times \mathrm{P}_{r}
$$


where $V_{r}$ is the water regulation and storage value, $W_{s}$ and $W_{r}$ are the flood adjustment capacity of swamp wetland and ponds, respectively, and $P_{r}$ is the cost of the reservoir. The cost of the reservoir is set at $0.67 ¥ / \mathrm{m}^{3}$.

\subsubsection{Microclimate Adjustment}

Wetlands can cool the air and increase air moisture content through evaporation. According to the relevant literature, the microclimate adjustment value of ponds and wetlands is $47.31 ¥ /$ ha and $1758.79 ¥ /$ ha, respectively [23].

$$
V_{w}=A \times P_{w}
$$

where $V_{w}$ is the microclimate adjustment value, $A$ is the area of wetlands and ponds, and $P_{w}$ is the price of the microclimate adjustment value.

\subsubsection{Pollution Degradation}

Wetlands have the strongest purifying capacity of all ecosystems. The pollution degradation value for wetlands is $1869.87 ¥ / \mathrm{ha}$, while the pollutant emission reduction value is $999.05 ¥ /$ ha.

$$
V_{d}=A \times P_{d}
$$

where $V_{d}$ is the pollution degradation value, $A$ is the wetland area, and $P_{d}$ is the pollution degradation value per unit.

\subsubsection{Biodiversity Protection}

Wetlands have the highest biodiversity in nature [24]. The biodiversity protection value of wetlands can be calculated as follows:

$$
V_{b}=A \times P_{d}
$$

where $V_{b}$ is the biodiversity protection value, $A$ is the wetland area, and $P_{b}$ is the biodiversity protection value per unit. The biodiversity protection service value of wetlands was taken to be $130.7 ¥ /$ ha [25].

\subsubsection{Scientific Culture}

Wetlands provide opportunities for multi-disciplinary studies spanning, for example, ecology, biology, and hydrology. The scientific culture value can be calculated as follows:

$$
V_{s}=A \times P_{s}
$$

where $V_{S}$ is the scientific culture value, $A$ is the wetland area, and $P_{S}$ is the scientific culture value per unit. The scientific culture service value of wetlands was taken as $25.47 ¥ /$ ha.

\subsubsection{Tourism Development}

The tourism development value of wetlands can be accounted for as follows:

$$
V_{t}=A \times P_{t}
$$

where $V_{t}$ is the tourism development value, $A$ is the wetland area, and $P_{t}$ is the tourism development value per unit. The tourism development service value of wetlands was assumed to be $367.63 ¥ / \mathrm{ha}$.

\subsubsection{Landscape Aesthetics}

The landscape aesthetics value of wetlands can be calculated according to the following formula:

$$
V_{l}=A \times P_{l}
$$


where $V_{l}$ is the tourism development value, $A$ is the wetland area, and $P_{l}$ is the tourism development value per unit. The tourism development service value of wetlands was assumed to be $140.42 ¥ / \mathrm{ha}$.

\section{Methods}

Because of the situation and function of different ecosystems, water requirements and incremental values of the ecosystem services are inexact. Some parameters cannot be expressed only in terms of exact numbers. Some of the parameters are random, such as water requirements and supply per unit (the values of water supply vary according to water requirement). However, some of the parameters need to be expressed as integers. In this study, a double-sided chance-constrained integer linear program (DCCILP) method has been proposed to deal with the random and integer parameters. The basic methods of DCCILP are as follows.

(1) Introduction to the linear program

A linear programming (LP) model can be formulated as [26]:

$$
\max f=C_{j} X_{j}
$$

subject to:

$$
\begin{gathered}
A_{j} X_{j} \leq B_{j} \\
X_{j} \geq 0
\end{gathered}
$$

where $f$ is the objective system value, $X$ is the decision variable, and $C, A$, and $B$ are parameters of $X$, and are real numbers.

(2) Integer linear program

Integer programming (IP) is a special type of linear program, which adds the attribute specification of integers to the optimization model [27-29]. It gradually evolved from the cutting plane method proposed by Gomory [30]. Integer linear program (ILP) refers to programming whose objective functions and constraints are linear.

Generally, integer programming can be classified into three types. In the pure integer linear program, all the decision variables are linear. In the mixed integer linear program, only a part of the decision variables are linear. In the 0-1 integer linear program, the values of all or part of the decision variable are either 0 or 1 .

(3) Double-sided chance-constrained programming theory

With the double-sided chance-constrained programming (DCCP) model, the parameters on both sides of the LP model are random variables, and can be expressed as follows [11]:

$$
\max f=C_{j} X_{j}
$$

subject to:

$$
\begin{gathered}
\operatorname{Pr}\left\{\sum_{j=1}^{n} A_{i j}(\omega) X_{j} \leq B_{j}(\omega)\right\} \geq 1-\theta_{i}, \quad i=1,2, \cdots m \\
A_{i j}(\omega) \sim N\left(\mu_{\mathrm{ij}}, \delta_{\mathrm{ij}}^{2}\right) \\
B_{j}(\omega) \sim N\left(v_{j}, \tau_{\mathrm{j}}^{2}\right) \\
D_{j} X_{j} \leq E_{j} \\
X_{j} \geq 0, \quad j=1,2, \cdots n
\end{gathered}
$$


where $\mu_{i j}$ and $v_{i j}$ are the expectations of $A$ and $B, \delta_{\mathrm{ij}}^{2}$ and $\tau_{i j}^{2}$ are standard variations of $A$ and $B$, and $1-\theta_{i}$ is the certain probability at which the constraints are satisfied.

To solve the DCCP model, the main route is to transform Equation (17) to its linearization form. Equation (17) can be approximated by the following inequality when $\theta_{i} \leq 0.5$ and $x_{j} \geq 0$.

$$
\left(\sum_{j=1}^{n} \mu_{\mathrm{ij}} x_{j}-v_{j}\right)+\Phi^{-1}\left(1-\theta_{\mathrm{i}}\right) \sqrt{\sum_{j=1}^{n}\left(\delta_{\mathrm{ij}} x_{j}\right)^{2}+\tau_{\mathrm{j}}^{2}} \leq 0, \quad \forall i
$$

where $\Phi^{-1}$ is the inverse cumulative distribution function of the standard normal random variable.

\section{DCCILP Model Based on the Incremental Value Optimization of Ecosystem Services}

The DCCILP model, based on the incremental value optimization of ecosystem services, was established by taking the 198 water bodies in western Jilin as a unit. The objective function is the maximization of the incremental value of ecosystem services. The decision variables are the function areas, including water requirement, fish farming area, crab farming area, reed area, and swamp wetland area. Regional water supply, the cultivation function of the ponds, $0-1$ issues, and water demand are taken as constraints. The objective function of the DCCILP model is presented as follows:

$$
\max V=\sum_{i=1}^{I} \sum_{j=1}^{J}\left(U v_{i j} \times A_{i j} \times Y_{i j}\right)
$$

subject to:

$$
\operatorname{Pr}\left\{\sum_{i=1}^{I} \sum_{j=1}^{J}\left(U w_{i j} \times A_{i j} \times Y_{i j}\right) \leq Q n\right\} \geq 1-\theta_{i}
$$

The sum of water demand for the water bodies should be less than the water supply that was set for each region in the optimization scheme. Water demand per unit and water supply for service regions are set as random numbers.

$$
A_{i z} \times Y_{i z} \times\left(A_{i w \max } \times Y_{i w}-A_{i w} \times Y_{i w}\right) \leq 0
$$

Water supply should give priority to fish and crab farming, then to reeds, and finally to swamp wetland water supply.

$$
q_{i j} \leq W_{i j}, \forall i, j
$$

Water supply for every pond should be less than the extreme value.

$$
Y=0 \text { or } 1, \forall i, j
$$

Optimization measures may not apply to all the service regions. Therefore, 0-1 integer programming can express the applicability of these measures, where 1 stands for applicable, and 0 stands for inapplicable. Based on Formula (22), the linearization form of inequality (24) can be transformed as follows:

$$
\left(U w_{i j} \times Y_{i j} \times \mu_{\mathrm{A}}-\mu_{\mathrm{Q}}\right)+\Phi^{-1}\left(1-\theta_{i}\right) \sqrt{\sum_{j=1}^{n}\left(\delta_{\mathrm{A}} x_{j}\right)^{2}+\tau_{\mathrm{Q}}^{2}} \leq 0
$$

\section{Results and Discussion}

This project addresses the incremental value of ecosystem services for tourism development, landscape aesthetics, food production, raw material production, water supply, carbon sequestration, atmosphere regulation, water regulation and storage, microclimate adjustment, and biodiversity 
protection. The optimization scheme is obtained using an assessment index system for the incremental value of the ecosystem services.

The incremental value of ecosystem services was $148.49 \times 10^{9}$ billion $¥$ before optimization, while incremental values increase this to $178.66 \times 10^{9} ¥$ after optimization. This indicates that the optimization scheme is feasible and can generate considerable additional benefits from ecosystem services. Taking Boluo Lake as an example: under the condition of meeting the largest water supply, the incremental value of the ecosystem service is $36.00 \times 10^{9} ¥$, while under optimization the value is $61.66 \times 10^{9}$ billion $¥$. The optimization scheme is shown in Table 2 .

Table 2. Optimization scheme for the ecosystem services’ incremental values for the IRSNP $\left(10^{9} ¥\right)$.

\begin{tabular}{ccccc|cccc}
\hline & \multicolumn{3}{c}{ Before } & \multicolumn{4}{c}{ After } \\
\cline { 2 - 9 } Subsystem & $\begin{array}{c}\text { Fish } \\
\text { Pond }\end{array}$ & $\begin{array}{c}\text { Crab } \\
\text { Pond }\end{array}$ & $\begin{array}{c}\text { Reed } \\
\text { Wetland }\end{array}$ & $\begin{array}{c}\text { Swamp } \\
\text { Wetland }\end{array}$ & $\begin{array}{c}\text { Fish } \\
\text { Pond }\end{array}$ & $\begin{array}{c}\text { Crab } \\
\text { Pond }\end{array}$ & $\begin{array}{c}\text { Reed } \\
\text { Wetland }\end{array}$ & $\begin{array}{c}\text { Swamp } \\
\text { Wetland }\end{array}$ \\
\hline Subsystem 1 & 4.05 & 1.87 & 3.76 & 2.63 & 3.39 & 1.04 & 3.78 & 5.35 \\
Subsystem 2 & 18.66 & 0.16 & 8.41 & 1.10 & 9.90 & 0.12 & 21.49 & 1.27 \\
Subsystem 3 & 0.94 & 1.20 & 1.41 & 2.41 & 0.72 & 0.62 & 3.30 & 9.34 \\
Subsystem 4 & 0.84 & 0.00 & 0.17 & 0.01 & 0.56 & 0.00 & 0.26 & 0.52 \\
Subsystem 5 & 0.00 & 0.00 & 0.00 & 1.60 & 0.00 & 0.00 & 0.00 & 3.28 \\
Subsystem 6 & 0.00 & 0.00 & 1.17 & 4.35 & 0.00 & 0.00 & 1.17 & 5.75 \\
Subsystem 7 & 0.18 & 0.07 & 1.48 & 0.13 & 0.13 & 0.07 & 1.74 & 0.26 \\
Subsystem 8 & 4.52 & 0.89 & 0.89 & 1.71 & 2.69 & 0.89 & 3.18 & 6.48 \\
Subsystem 9 & 4.90 & 0.13 & 2.47 & 2.95 & 2.87 & 0.13 & 2.47 & 6.99 \\
Subsystem 10 & 6.44 & 0.16 & 0.68 & 2.11 & 4.46 & 0.16 & 0.68 & 6.66 \\
Subsystem 11 & 0.00 & 0.00 & 0.99 & 0.86 & 0.00 & 0.00 & 2.19 & 1.07 \\
Subsystem 12 & 1.95 & 8.36 & 10.61 & 29.25 & 1.30 & 5.63 & 10.82 & 35.37 \\
Subsystem 13 & 0.00 & 0.41 & 0.68 & 0.31 & 0.00 & 0.18 & 0.69 & 0.81 \\
Subsystem 14 & 0.78 & 2.18 & 1.00 & 2.36 & 0.60 & 1.19 & 1.73 & 3.36 \\
Subsystem 15 & 0.83 & 0.29 & 0.73 & 0.32 & 0.57 & 0.19 & 1.00 \\
Summary & 44.09 & 15.73 & 34.45 & 52.09 & 27.19 & 10.20 & 54.49 & 0.54 \\
Total & & & 146.36 & & & & 178.92 & 87.04 \\
\hline
\end{tabular}

\subsection{Area Proportion of the Functional Areas}

The proportion of the area taken up by fish ponds, crab ponds, reeds, and swamp wetlands is $40.10 \%, 11.71 \%, 18.31 \%$, and $29.87 \%$ respectively, before optimization (shown in Figure $2 a$ ). The result indicates that fish ponds take up the highest proportion of the area, followed by swamps. After optimization, swamp wetlands take the highest ratio (44.88\%) instead of fish ponds, an increase of $15.01 \%$ (shown in Figure $2 b$ ). The IRSNP can bring more water into the ponds and lakes, increasing the storage and providing more options for plantation and cultivation, and the optimization model can select reasonable operating procedures to obtain a clear improvement in ecological benefits in the planning area.

(a)

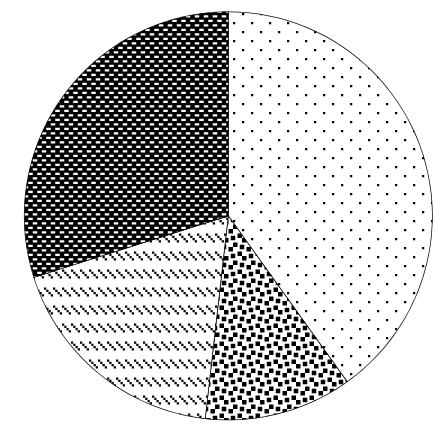

$\square$ Fish pond Grab pond $₫$ Reed : Swamp (b)

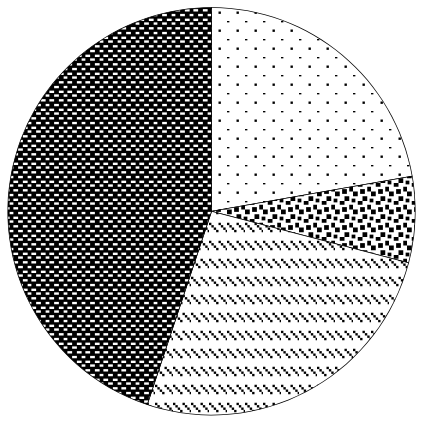

$\odot$ Fish pond $\mathrm{g}$ Crab pond $₫$ Reed : Swamp

Figure 2. Proportion of areas of fish ponds, crab ponds, reed fields, and swamp wetlands: (a) before optimization; and (b) after optimization. 


\subsection{Ecological Benefit of the Functional Areas}

The ecological benefits of fish ponds, crab ponds, reeds, and swamp wetlands expressed as percentages are $30.12 \%, 10.75 \%, 23.54 \%$, and $35.59 \%$, respectively, before optimization (Figure $3 a$ ). This changes to $15.20 \%, 5.70 \%, 30.46 \%$, and $48.65 \%$, respectively, in the optimization scheme (Figure $3 \mathrm{~b}$ ). The results show that the ecological benefits from swamp wetlands are the highest for all four functional areas, and increase from $35.59 \%$ to $48.65 \%$ after optimization. The reason for this is that swamp wetlands can bring multiple benefits, such as carbon sequestration, gas regulation, flood mitigation, microclimate modification, pollution degradation, biodiversity protection, scientific culture, tourism development, and landscape aesthetics. Fish ponds have the largest decrease in the optimization scheme, down by $14.92 \%$. Fish ponds provide fewer ecological services than swamp wetlands, and therefore the optimization model increases the proportion of swamp wetlands and decreases the ratio of fish ponds to promote the total ecological benefit (an increase of $22.25 \%$ ) by optimizing the planned construction.

(a)

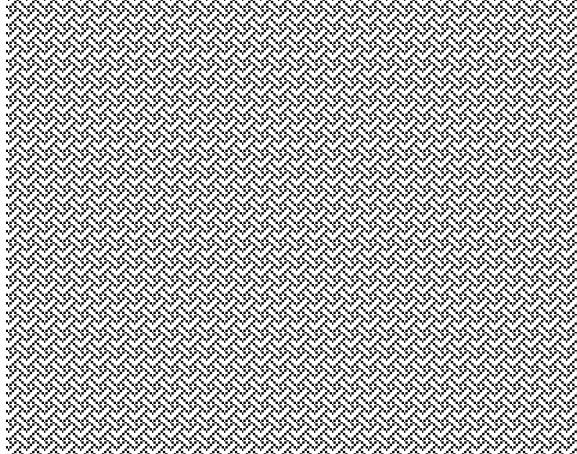

(b)

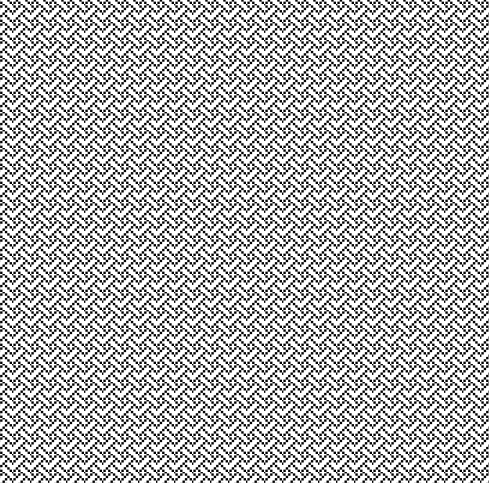

Figure 3. Proportion of ecological benefits for fish ponds, crab ponds, reed fields, and swamp wetlands: (a) before optimization; and (b) after optimization.

\subsection{Ecological Benefit Proportions for Different Services}

\subsubsection{Ecological Benefit Proportions for First-Class Indices}

The percentage of supply services, adjustment services, support services, and culture services changed from $28.04 \%, 29.33 \%, 31.52 \%$, and $11.11 \%$, respectively, before optimization, to $14.71 \%, 34.14 \%$, $41.04 \%$, and $10.11 \%$, respectively, after optimization (Figure 4 ). The proportion of supply services decreased by $13.33 \%$ compared with the scheme before optimization, while support services increased by $9.52 \%$, and thus make the largest contribution to total ecological benefits. The original scheme gives priority to supply and production services, while the optimization scheme promotes the ratio of adjustment services, and the total ecological benefits increase accordingly.
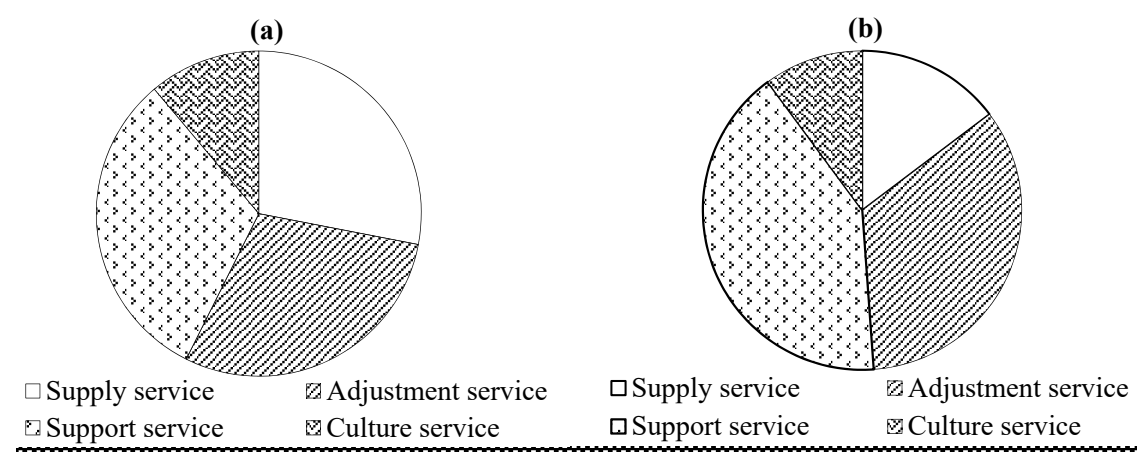

Figure 4. Proportion of supply services, adjustment services, support services, and culture services: (a) before optimization; and (b) after optimization. 


\subsubsection{Ecological Benefit Proportions for the Second-Class Indices}

The twelve second-class indices include food production, raw material production, water supply, carbon sequestration, atmosphere regulation, water regulation and storage, microclimate adjustment, pollution degradation, biodiversity protection, scientific culture, tourism development, and landscape aesthetics (shown in Figure 5). Among all the twelve second-class indices, pollution degradation accounts for the highest proportion before optimization and rise to $39 \%$ after optimization, while the relevant benefit increased by $2.67 \times 10^{9} ¥$. The ecosystem services' incremental value of microclimate adjustment has the same varying tendency. Table 2 shows that the total ecosystem services' incremental values for the IRSNP shows a dramatic increases, which indicates that the optimal scheme can realize win-win between ecologic environment protection and economic growth.

Food production refers to fish and crab cultivation in the lakes and ponds. Their valuation proportion affects local output directly, and can be calculated using the market value method. In the optimization scheme, the proportion of food production decreased by $9.37 \%$, while the relevant benefit declined by $1.05 \times 10^{9} ¥$. The reason is that food production gives priority to economic production but not biodiversity, which should be decreased properly.

For raw material production, reed is the main resource. Western Jilin is the major production area for reeds in the Jilin province. Reed rods provide economic and social benefits, and can be used for making materials such as paper, rayon, and artificial cotton. The proportion of food production increases by $0.13 \%$ while the relevant benefit increases by $3.90 \times 10^{7} ¥$. Reed is not only an economic resource, but is also an ecological resource. It has the capacity to prevent secondary salinization; prevent the accumulation of stranded sediments, toxic or harmful substances, and eutrophication materials; and can effectively reduce environmental pollution. It can store carbon in organic form and reduce greenhouse effects. Reed areas also provide a favorable habitat for flora and fauna, thus encouraging biodiversity.

Water supply benefits in the form of water for residential use, agricultural production, and industrial production, can be determined using the market value method and the shadow project approach. The proportion of food production decreased by $4.10 \%$ while the relevant benefit declined by $4.61 \times 10^{8} ¥$, indicating that in some of the service regions, water resources meet local living requirements and production demands, and that water supply can be adjusted to provide development opportunities for other services.

Carbon sequestration benefits from the rich biological resources in wetlands. The biomass of the reed wetland is approximately $300 \mathrm{~kg} / \mathrm{ha}$, and is approximately $50 \mathrm{~kg} / \mathrm{ha}$ for the swamp wetland. The extensive areas of reed and marsh realize carbon sequestration through photosynthesis. In the optimization results, the area proportion of reed and marsh increases by $0.06 \%$, which leads to a carbon sequestration benefit increase of $1.56 \times 10^{7} ¥$. This indicates that a very small increase in reed and marsh areas can significantly increase biomass production and carbon sequestration.

Wetlands can regulate the atmosphere by releasing oxygen. Because of the abundant biomass in the study area, large amounts of oxygen are released with carbon sequestration, and can be calculated by the market value method. The percentage of atmosphere regulation benefit increases by $0.54 \%$ in the optimization scheme, resulting in a significant increase in ecological benefits of $1.54 \times 10^{8} ¥$. This shows that an increase in wetland biomass can simultaneously improve carbon sequestration and atmosphere regulation.

Water regulation and storage benefits include flood mitigation and reserving large amounts of water for domestic and production needs in dry seasons. Water regulation and storage benefits in the optimization scheme declined by $1.15 \%$, which lead to a decrease in benefits of $2.99 \times 10^{7} ¥$. The explanation for this is that some of the water bodies can mitigate floods and store water, while others do not. Thus, appropriate optimization in wetland areas has the potential to achieve more water conservation and supply benefits.

Microclimate adjustment is reflected in the cooling and humidifying function of wetlands for local residents by water evaporation. In the optimization scheme, the proportion of microclimate adjustment 
benefits increased by $5.47 \%$, resulting in a $1.62 \times 10^{9} ¥$ increase for these benefits. The result indicates that the benefits from microclimate adjustment are clear, and the total ecological benefit will increase by optimizing the wetlands associated with lakes and ponds.

Wetland ecosystems had the strongest purifying capacity. This involves the pollution degradation benefit of wetland systems. Plants in wetlands play a significant role in pollution assimilation, metabolism, and decomposition, as well as eutrophication reduction. The proportion of pollution degradation benefits increased by $9.77 \%$ under optimization, thus contributing $2.68 \times 10^{9} ¥$ more than the original scheme did. In the optimization scheme, a large area of wetland has been recovered and shows significant pollution degradation benefits.

Biodiversity protection benefits mainly refer to the richness of wetlands for biodiversity. The percentage of biodiversity protection benefits declined by $0.25 \%$ from the original scheme, which led to a decrease in biodiversity protection benefits of $4.47 \times 10^{7} ¥$. The reason is that appropriate decreases in wetlands can improve water storage, and obtain higher total benefits.

Wetlands can also be used for various kinds of research activities, such as monitoring, testing, and contrasting. Insights into the evolution of historical characteristics, species, biocenosis, habitat, landscape, and ecosystems can be obtained through traces of ecological processes preserved by wetlands. In the optimization scheme, the proportion of scientific culture benefits decreased by $0.05 \%$, leading to a decline in benefits of about $8.70 \times 10^{6} ¥$. Thus, although the adjustment of water quantity in the lakes and ponds has an impact on scientific culture benefits, the influence is negligible.

(a)

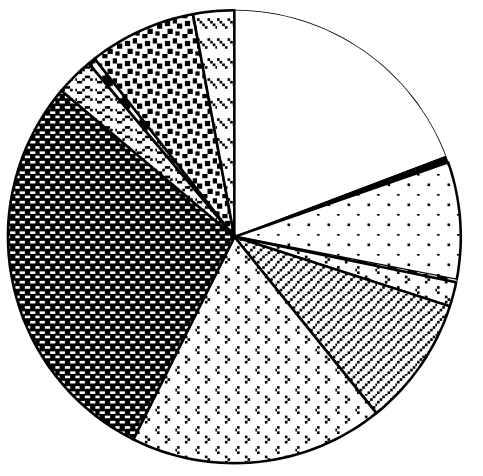

$\square$ Food production

- Raw material production

$\square$ Water supply

a Carbon sequestration

$\square$ Atmosphere regulation

$\checkmark$ Water regulation and storage

घMicroclimate adjustment

⿴囗十 Pollution degradation

曰Biodiversity protection

Scientific culture

Tourism development

@Landscape aesthetics

(b)

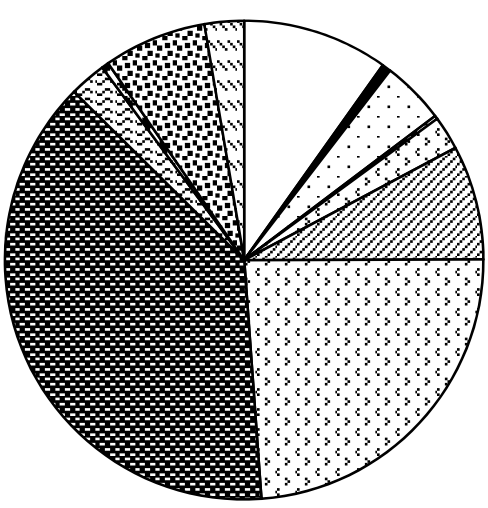
$\square$ Food production
- Raw material production
$\square$ Water supply
- Carbon sequestration
Atmosphere regulation
七 Water regulation and storage
๑. Microclimate adjustment
Pollution degradation

Figure 5. Proportion of service benefits for second-class indices: food production, raw material production, water supply, carbon sequestration, atmosphere regulation, water regulation and storage, microclimate adjustment, pollution degradation, biodiversity protection, scientific culture, tourism development, and landscape aesthetics services: (a) before optimization; and (b) after optimization. 
Tourism development and landscape aesthetics benefit from the unique ecosystems and endangered species that the wetland system has. Thus, wetlands provide significant tourist attractions and relaxation benefits. The ratio of tourism development and landscape aesthetics benefits declined by $0.69 \%$ and $0.26 \%$, respectively, in the optimization scheme, which led to a decrease of $1.26 \times 10^{8}$ and $4.80 \times 10^{7} ¥$, respectively.

The optimization model places emphasis on ecological benefits, and thus the economic benefits declined accordingly. Overall, the total benefits increased by $22.25 \%$, which equates to $3.26 \times 10^{9} ¥$ more than the original scheme.

\section{Conclusions}

The DCCILP method has been proposed based on traditional ILP and the double-sided CCP methods, and applied to an optimization research on the incremental value of ecosystem services, based on the Interconnected River System Network Project in Western Jilin Province. The DCCILP can express interval information, integer parameters and double-hand-side random variables simultaneously, that can settle various uncertainties during the flood resources utilization process. This article demonstrates that the incremental value of ecosystem services can be generated from the flood process by using IRSNP reasonably, and after applying the optimization scheme obtained from the DCCILP method, the incremental value can increase up to $20.38 \%$ compared to before application. This is the first attempt to apply DCCILP to a flood resource management problem, and the integrated method can also be applied to many other environmental problems.

Acknowledgments: Supported by Interconnected River System Network Project established by Jilin provincial government; China.

Author Contributions: Baofeng Cai and Yu Li designed the framework; Yu Li provided data support; Xianen Wang analyzed the data; Baofeng Cai wrote the paper.

Conflicts of Interest: No conflict of interest.

\section{References}

1. Zhang, H.; Ha, M.H.; Xing, H.J. Chance-constrained programming on sugeno measure space. Expert Syst. Appl. 2011, 38, 11527-11533. [CrossRef]

2. Chen, L.C.; Ma, X.Z.; Li, S.F. Analysis on economic value of wetland. Environ. Sci. Manag. 2006, 31, 157-158.

3. Tong, S. Evaluation of ecosystem services values of Henglong wetland in Liaoning Province. Inn. Mong. For. Investig. Des. 2012, 2, 18-19. (In Chinese)

4. Zhang, X.L.; Ye, S.Y.; Yin, P.; Gu, S.Q. Ecosystem service value and its temporal change of coastal wetland in southern Laizhou Bay. Ecology 2008, 27, 2195-2202. (In Chinese)

5. Jiang, H.; Cheng, L.L.; Yin, C.B.; Gu, S.Q. Research on Ecosystem Services Valuation in Hongze Lake Wetland. Res. Agric. Mod. 2008, 27, 2195-2202.

6. Yao, Y.M.; Xiong, J.J.; Deng, X. Evaluation of ecosystem services values of Xuefeng Lake National Wetland Park. Hunan For. Sci. Technol. 2015, 42, 70-73.

7. Shao, N.P.; Liu, X.P.; Qu, X.Y. Valuation of lake wetland ecosystem services of Yinchuan City. Ecology 2008, 27, 1625-1630. (In Chinese)

8. Zhao, R.; Dong, Y.X.; Tan, Z.W. Review of Service Value Evaluation of Aquatic Ecosystem. Environ. Sci. Surv. 2014, 33, 33-39.

9. Zeng, X.G.; Sun, C.Y.; Han, W. Research on economic value of wetland. Ecol. Econ. 2002, 9, 51-54.

10. Ji, Y.; Huang, G.H.; Sun, W. Inexact left-hand-side chance-constrained programming for nonpoint-source water quality management. Water Air Soil Pollut. 2014, 225, 1895-1908. [CrossRef]

11. Ji, Y.; Huang, G.H.; Sun, W. Inexact Left-Hand-Side Chance-Constrained Programming for Nonpoint-Source Water Quality Management. Water Air Soil Pollut. 2015, 29, 3079-3094. [CrossRef]

12. Zyoud, S.H.; Kaufmann, L.G.; Shaheen, H.; Samhan, S.; Hanusch, D.F. A framework for water loss management in developing countries under fuzzy environment: Integration of Fuzzy AHP with Fuzzy TOPSIS. Expert Syst. Appl. 2016, 61, 86-105. [CrossRef] 
13. Yang, N.; Wen, F. A chance constrained programming approach to transmission system expansion planning. Electr. Pow. Syst. Res. 2005, 75, 171-177. [CrossRef]

14. Li, Y.P.; Huang, G.H.; Nie, S.L.; Qin, X.S. ITCLP: An inexact two-stage chance-constrained program for planning waste management systems. Res. Conserv. Recycl. 2007, 49, 284-307. [CrossRef]

15. Pang, B.L.; Cui, L.J.; Ma, M.Y.; Li, W. Carbon sequestration service valuation of Zhalong wetland ecosystem. Ecology 2014, 33, 2078-2083. (In Chinese)

16. Li, H.; Cai, Y.L. The predicted evaluation of the impact of eco-service value of the planning of wetland park. Territory Nat. Res. Study 2008, 2, 56-58.

17. Zhou, L.F.; Wu, Y.; He, X.M. Assessment of ecosystem services values of Shifo Temple constructed wetlands. Pearl River 2015, 35, 84-87. (In Chinese)

18. Fan, X.; Meng, L.F.; Liu, C.; Xu, H. Evaluation of ecosystem services values of Gaoyou Lake. J. Econ. Water Resour. 2015, 1, 14-17.

19. Fan, G.H.; Zhong, D.H.; Yan, F.G.; Yue, P. A hybrid fuzzy evaluation method for curtain grouting efficiency assessment based on an AHP method extended by D numbers. Expert Syst. Appl. 2016, 44, 289-303. [CrossRef]

20. Sabaghi, M.; Mascle, C.; Baptiste, P.; Rostamzadeh, R. Sustainability assessment using fuzzy-inference technique (SAFT): A methodology toward green products. Expert Syst. Appl. 2016, 56, 69-79. [CrossRef]

21. Zhao, J. Contingent Valuation of Ecosystem Services: Theory, Methods and Applications. Ph.D. Thesis, East China Normal University, Shanghai, China, 2005. (In Chinese)

22. Chen, L.J. The evaluation research of Hongze lake wetland ecosystem service function value. Resour. Environ. Dev. 2009, 2, 29-31.

23. Xie, G.D.; Zhen, L.; Lu, C.X.; Xiao, Y.; Chen, C. Expert knowledge based valuation method of ecosystem services in China. J. Nat. Resour. 2008, 23, 911-919.

24. Yan, C.G.; Zhang, M.X.; Wang, J.C. Study on valuation indexes and methods of wetland biodiversity in China. For. Resour. Manag. 2000, 1, 41-46.

25. Costanza, R.; d'Arge, R.; De Groot, R.; Farber, S.; Grasso, M.; Hannon, B.; Limburg, K.; Naeem, S.; O'neill, R.V.; Paruelo, J.; et al. The value of the world's ecosystem services and natural capital. Nature 1997, 387, $253-260$. [CrossRef]

26. Huang, G.H.; Baetz, B.W. A gray linear-programming approach for municipal solid-waste management planning under uncertainty. Civ. Eng. Environ. Syst. 1992, 9, 319-335. [CrossRef]

27. Kato, K.; Sakawa, M.; Katagiri, H.; Perkgoz, C. An interactive fuzzy satisficing method based on fractile criterion optimization for multiobjective stochastic integer programming problems. Expert Syst. Appl. 2010, 37, 6012-6017. [CrossRef]

28. Fetanat, A.; Shafipour, G. Generation maintenance scheduling in power systems using ant colony optimization for continuous domains based 0-1 integer programming. Expert Syst. Appl. 2011, 38, 9729-9735. [CrossRef]

29. Tavana, M.; Keramatpour, M.; Santos-Arteaga, F.J.; Ghorbaniane, E. A fuzzy hybrid project portfolio selection method using Data Envelopment Analysis, TOPSIS and Integer Programming. Expert Syst. Appl. 2015, 42, 8432-8444. [CrossRef]

30. Gomory, R.E. Outline of an algorithm for integer solutions to linear programs. Bull. Am. Math. Soc. 1958, 64, 275-278. [CrossRef]

(C) 2017 by the authors. Licensee MDPI, Basel, Switzerland. This article is an open access article distributed under the terms and conditions of the Creative Commons Attribution (CC BY) license (http:// creativecommons.org/licenses/by/4.0/). 